\title{
A Ironia como uma das Saídas do Teatro Pós-Dramático
}

\author{
Eduardo Almeida Santos \\ Universidade Federal do Rio de Janeiro - UFRJ \\ Email: eduardoteffe@gmail.com
}

O presente trabalho aborda as possibilidades do texto teatral que se constrói a partir do drama moderno até a obra considerada pós-dramática, quando o teatro contemporâneo se vê diante da crise e da possibilidade do fim do drama como elemento norteador das criações de encenação ou de dramaturgia. Logo, os diversos elementos que convergiam na construção deste norte se encontraram em suspensão. Ao refletir sobre uma série de obras cênicas contemporâneas, uma das saídas apontadas e analisadas por este estudo será o uso e o conceito da "Ironia" principalmente no texto Insulto ao público, de Peter Handke. É a ironia que atua no imperfeito, no contraditório e no vazio - que são partes constantes da dramaturgia de nosso tempo.

Palavras-chave

Ironia. Pós-dramático. Crise do drama.
The present work approaches the possibilities of the theatrical text that is constructed from the modern drama until the work considered post-dramatic, when the contemporary theater is faced with the crisis and the possibility of the end of the drama as a guiding element of the creations of staging or dramaturgy. Therefore, the diverse elements that converged in the construction of this north became suspended. In reflecting on a series of contemporary plays, one of the alternatives pointed out and analyzed by this study will be the use and the concept of "Irony", mainly in Peter Handke's text Insult to the Public. It is the irony that acts in the imperfect, in the contradictory and the void, which are constant parts of the dramaturgy of our time. Keywords

Irony. Post-dramatic. Drama Crisis. 


\section{Introdução}

O teatro enquanto drama é uma arte em constante crise. Desde o momento em que Eurípedes em sua obra apresenta uma atitude cética, representações das efemeridades da alma humana e personagens cujos sentimentos intensos os levam à loucura, há o questionamento da arquitetura dramatúrgica trágica. Passando pelos mais diversos momentos de esgarçamento das possibilidades dramáticas ao longo da história (materializadas em Seis personagens à procura de um autor (1921), de Pirandello, obra na qual "os personagens" dizem que os atores não conseguiriam dar conta do verdadeiro drama deles) até chegar à contemporaneidade, ou na crise instituída pelo drama por questionar a cena.

Existehoje a denominação de teatro "pós-dramático" formulada pelo crítico e professor de teatro alemão Hans-Thies Lehmann ${ }^{1}$ em sua obra Postdramatisches Theater, publicada originalmente em 1999, na Alemanha. Este livro mapeia procedimentos e estilos de diversas modalidades cênicas sob o conceito de "teatro pós-dramático", que abrange múltiplas e heterogêneas obras encenadas entre os anos de 1970 e 1990. Deste período, merecem destaque o dramaturgo alemão Heiner Müller, os encenadores Robert Wilson, Tadeusz Kantor, Klaus Michael Grüber, Robert Lepage e Jan Lauwers, além de grupos como "Théâtre du Soleil" (França), "Gob Squad" (Inglaterra), "Societas Raffaello Sanzio" (Itália) e "Baktruppen" (Holanda).

1 Lehmann esteve no Brasil em 2006, participando de várias atividades ligadas ao cinquentenário do falecimento do dramaturgo alemão Bertolt Brecht. Mais recentemente, retorna ao Brasil em 2009, lançando seu livro Teatro Pós-Dramático e em 2010 realiza palestras e seminários em universidades em São Paulo/SP, Goiânia/GO, Porto Alegre/RS, Florianópolis/ SC e Salvador/BA.
O conceito defendido pelo autor apoiava-se na observação do fim da crença no drama enquanto conflito, fábula e processo desenrolar/desenvolver-se - como um dos elementos estruturantes essenciais do teatro. Nas artes cênicas posteriores, o drama encontrou-se em crise. Mas esta libertaria o teatro para uma utilização criativa das possibilidades do texto (e até do não-texto) e das modernas tecnologias audiovisuais. Além de uma intensa incorporação de elementos das outras formas de arte, oriundos das artes plásticas, música, dança, cinema, áudio visuale performance.

Esta mudança já estava em curso. Em 1956, o livro Teoria do Drama Moderno (que analisa o período da literatura teatral de 1880 a 1950), de autoria de Peter Szondi, faz observações a este respeito sobre a dramaturgia de Thecov, Ionesco, Piradelo, dentre outros. A extenuação de tempo, fragmentação do personagem, questionamento da possibilidade teatral já estavam presentes. O que se vê na teoria de Lehmann é o aprofundamento deste tema somado às novas (e talvez infinitas) possibilidades de encenação. Assim, o teatro pós-dramático é a distensão-tensão-junção das formas cênicas e textuais do teatro tradicional, perpassadas pelos movimentos de arte de vanguarda do século $X X$.

Para exemplificar estes procedimentos: a arte plástica não poderia ser mais a mesma depois do Urinol, de Duchamp, assim como a música. É inegável a abertura criada por uma música toda feita por silêncio -433 , de John Cage, ou ainda as encenações de Beltold Brecht, que buscavam quebrar a ilusão teatral, ou as peças de Beckett, em que a ação da peça era exatamente a inação (cujos trabalhos questionavam o teatro vigente tanto pela encenação como pelo texto). Nestas ramificações, 
inserem-se as obras de Peter Handke, o qual será analisado posteriormente neste ensaio, através do exemplo de um texto seu chamado Insulto ao Público.

Como já foi dito de forma específica, a dramaturgia teatral, principalmente aquela vinculada ao teatro clássico burguês, viu surgir um novo tipo de teatro que implementou novos paradigmas na cena e no texto de forma acentuada a partir dos anos 1980. Lehmann (1999) considera que o teatro pós-dramático seria uma extensão ou ainda uma extenuação do teatro da estética pós-moderna dos anos de 1960. Afirma o autor, considerando as antigas teses teatrais, que, do teatro elisabetano ao burguês do final do século $X X$, o teatro funcionara sempre dentro dos princípios da mimesis e da katharsis aristotélica.

Logo, o rompimento destes paradigmas ${ }^{2}$ (e de alguns outros) realocou o teatro longe de onde sempre esteve e o deixou àprocura de si mesmo. Deslocar-seda zona tradicional problematizou diversos aspectos do teatro, mas também criou possibilidades e alternativas para reconstruir o(s) diálogo(s) - ou até mesmo questioná-lo(s) - com o seu público. Cabe notar que a crise é, muitas vezes, o elemento necessário para se buscar, apontar e/ou criar novos caminhos. A dessublimação da função de porta-voz da esfera pública crítica ou ainda o deslocar da representação da "realidade" (a sua sustentação em grande parte no século $\mathrm{XX)}$ permitiram ao teatro seguir a direção de novos caminhos.

É irônico até pensar nesta possibilidade (porém, muitas vezes, é a ironia que salva), mas, se por um lado, o teatro perdeu o seu fascínio enquanto arte ilusória diante dos grandes

2 Além, é claro, do surgimento da fotografia e do cinema e sua melhor capacidade técnica para representar o "real". meios de comunicação de massas, por outro, pôde se tornar mais "teatro" ao longo do século XX e inventar ou reusar antigas formas de ação teatral - pôde propor novas alternativasde comunicação para contrapor-seao poder absoluto das pseudo esferas públicas da mídia e estabelecer seus espaços próprios de comunicação diferenciada. Foi perdendo que ele ganhou!

O distanciamento entre o teatro e o drama - enquanto arte do aqui e agora- possibilitouuma redefinição do status do diretor e do dramaturgo, o qual não exige uma dependência recíproca ou centralizadora e possibilita uma reconfiguração e independência recíproca dos papéis dos vários textos da cena, seja a cenografia, a dramaturgia, a direção etc.

Em relação à não linearidade (a ausência de uma fábula) dentro da estética pós-dramática, Lehmann (1999, p. 100) afirma que

[...] Foi determinante para a estética
teatral o deslocamento da obra para o
acontecimento. É certo que o ato da
observação, as reações e as 'repos-
tas' latentes, ou mais incisivas dos
espectadores desde sempre haviam
constituído um fator essencial da re-
alidade teatral, mas nesse momento
se tornam um componente ativo do
acontecimento, de modo que a ideia
de uma construção coerente de uma
obra teatral acaba por se tornar obso-
leta: um teatro que inclui as ações e
expressões dos espectadores como
um elemento de sua própria constitui-
ção não pode se fechar em um todo
nem do ponto de vista prático nem te-
órico. Assim, o acontecimento teatral
torna explícitas tanto a processualida-
de que lhe é própria quanto à imprevi-
sibilidade nela implícita.

Esta nova forma de realizar teatro não procurava suscitar a adesão do espectador, mas provocar a sua percepção ou emoção significativa. Dialética, distanciamento, absurdo e 
ironia passaram a compor o espaço, deixando as regras vigentes do drama até então. Foi a falta de crença no drama como elemento necessário a uma boa obra que permitiu o surgimento dos outros elementos. É importante salientarque o sublime, o perfeito, gera distanciamento de procedimento (por outro lado, quando a intimidade ou imperfeição avança, naturalmente a "aura" recua). Foi esta perda que permitiu ao que até então estava estabelecido, tornar-se dialético. Incorporar o distanciar-se como efeito, o absurdo como aceitável e a ironia não mais como "apenas" uma serva do jogo de linguagem, mas uma saída possível de construção cênica.

De forma específica, este artigo busca exemplificar alguns destes procedimentos, principalmente a ironia, usando como objeto de estudo a peça Insulto ao Público, de Peter Handke. Cabe ainda, investigar a relação entre a ironia presente nesta obra e o ceticismo diante do teatro.

Peter Handke constrói sua obra teatral a partir de um tensionamento dos códigos que regem a relação palco-plateia. Em Insulto ao Público, a tensão começa com a própria ênfase na construção da ilusão, por parte da plateia, de que algo será apresentado. Nas didascálias iniciais, ele apresenta uma rubrica (que depois será desconstruída ao abrir do pano) que indica que "por trás da cortina baixada dão-se retoques a algum cenário e atores preparam-se para começar" (Handke, s/d, p. 1). Sugerem-se barulhos de mesas arrastadas, sussurros de um chefe de máquina, entre outros signos do teatro. Mas, ao abrir as cortinas, apesar de toda sonorização indicada, o público percebe que nada daquilo existia. Há apenas atores (que ele nem indica quantos) e um palco vazio de dispositivos cenográficos.
Todas as convenções ligadas ao teatro estiveram presentes- dos "lanterninhas" aos ruídos dos bastidores-e existiram até o exato momento em que a cortina se abriu e os atores entraram em cena. Quando isto ocorre, o vazio contrapõe-se à expectativa. A peça cria a ilusão do sublime, mas o que entra em cena é o "pobre" e o grotesco da representação promovendo uma espécie de niilismo recuperador. A construção de uma situação familiar, por exemplo, é enlaçada pela ironia e pelo grotesco. A plateia, que em tese estava preparada para se deixar entreter, passa a dialogar com uma outra instância do lugar teatral.

Já nas primeiras frases, o jogo entre ouvir e ver e a enxurrada de afirmações e negações categóricas continuam a desmontar as expectativas da plateia. O desmonte do edifício teatral é executado pelo elenco, que nega aos espectadores aquilo que estes esperame recusa-se a fazer sua parte: "Poderíamos apresentar-lhes um interlúdio. "[...] Mas nós não representamos nada diante dos senhores. Não imitamos nada " (Handke, s/d, p. 2).

$A$ inesperada ausência de cenários e figurinos, a negação da representação e a entrada dos atores ensaiando insultos e negando o espetáculo cênico (mas já sendo espetáculo cênico) encaixam-se entre a melancolia e o humor. De forma dialética e irônica, articulam-se entre a racionalidade e a subjetividade, afirmando logo no início do texto: "Esta peça é um prólogo", contradizendo e articulando as palavras entre texto e cena. Ao ironizar a palavra e encaixar a peça por meio dela como o prólogo (e sendo a peça, peça), é nítida a ironia ácida no material teatral. Desta forma, lança-se uma pergunta ao expectador (que, ao mesmo tempo, é um confronto): se a peça é o prólogo, onde está a peça de fato? 
Enquanto isto, não se responde o texto, caminha-se na direção de apontar ironias de duplos significados que abrem e articulam a "realidade do mundo" e a "realidade cênica" através de frases que se contradizem, como "Os senhores não verão um espetáculo! Os senhores verão um espetáculo" e "[...] os senhores ouvirão aqui o que geralmente viram. Os senhores ouvirão aqui o que geralmente não viram", ou ainda a frase dita em uma representação que nega a representação "Os senhores não verão representação alguma" (Handke, s/d, p. 2). Os "atores" apresentam uma materialidade cênica que se constrói sobre a negação de si mesma. É uma espécie de ironia libertária que vai abrindo uma caixa da Dialética.

As tensões criadas por esta massa de palavras adquirem na representação uma materialidade independente de qualquer sentido pela desconexão entre a imagem e o verbo e, logo, criam uma experiência sensorial única que corresponde à visão de Lehmann sobre o teatro pós-dramático - "é mais presença que representação, mais experiência partilhada do que experiência transmitida, mais processo do que resultado, mais manifestação do que significação, mais impulsão de energia do que informação" (Lehmann, 1999, p. 134).

A consciência constante de sua condição de obra teatral, a dinâmica criada na relação com a platéia, as contradições constantes, as ironias tais como a afirmação de que "já que em nenhum momento se rompe a regra das três unidades então se trata de um texto clássico" (Handke, s/d, p.7) contribuem para a produção de uma obra com características pós-dramáticas, que só se realiza completamente na vivência do encontro entre público e elenco. Handke (apud Materno, 2009), mestre nesta carpintaria, classifica-a como peça falada, designação que

parece ser um contraponto a ideia de peça encenada, representada e parece querer separar, problematicamente, dois elementos que, a princípio (ou numa concepção mais tradicional) constituem, no teatro, uma unidade: a visão e a escuta.

É preciso voltar a uma característica importante do teatro pós-dramático, tanto para dramaturgos como para encenadores: é a consciência de que $\mathrm{o}$ ato teatral se configura enquanto acontecimento do encontro, ou seja, a estética pós-dramática apropria-se da situação teatral e do imediatismo cênico. Logo, o momento artístico constitui-se e constrói-se durante a imediata presença entre artistas e seu respectivo público. Forma e procedimento são explorados de modo consciente pelos artistas contemporâneos. Já não se busca mais, como era o caso do drama burguês, criar uma atmosfera de ilusão, em que o palco pretende ser o mundo e a encenação um recorte da vida real que se encontra além das paredes do edifício teatral - mas sim, situar concretamente o teatro no aqui e agora.

O teatro pós-dramático (assim como a peça Insulto ao Público, de Handke) indaga, portanto, o alcance do impacto da arte na vida, bem como o da vida na arte. O teatro de agora, consciente de sua própria característica ficcional, começa a jogar com elementos hiper-realistas que visam confundir o espectador e, por vezes, os próprios artistas. Até que ponto, determinado acontecimento fez parte do espetáculo ensaiado, e, até que ponto, ele deu-se de modo espontâneo e com um grau de realidade pragmática mais alto? Isso ocorre, entre outros motivos, devido ao fato de que agora o espectador torna-se co-autor da cena, do conjunto 
dramático, um participante que apesar de não interpretar, não fazer de conta, age como o faria em seu dia a dia.

A ideia de que o teatro delimita a situação teatral as fronteiras entre arte e vida começa a diluir-se; é necessário, todavia, destacar que o foco principal não se encontra como ocorreu com as performances dos anos 60 , em criar uma arte que se configure como a própria vida real. A indagação sobre os limites entre arte e vida visa identificaras lacunas, contradições e rupturas nos sistemas artístico e social.

Através de tais circunstâncias, a delimitação precisa entre o que é o teatro (momento ensaiado que faz parte de uma ficção) e o que constitui o presente pragmático parece não ser mais tão facilmente detectável. Tal esfumaçamento entre arte e vida é também fruto de um teatro que tem rompido com as paredes do edifício teatral, fazendo espetáculos em lugares múltiplos e principalmente, propondo pontos de vista diversos aos seus espectadores. Creio ser interessante destacar dentro de qual contexto social esse teatro parece ter emergido, e como, então, sua nova forma pretende dialogar com este contexto. Para Guy Debord (1997, p. 13-14), é possível identificar a sociedade contemporânea enquanto "sociedade de espetáculo", pois segundo o autor

Toda a vida das sociedades nas quais reinam as modernas conduções de produção se apresenta como uma imensa acumulação de espetáculos. Tudo que era vivido diretamente tornou-se uma representação. [...] 0 espetáculo apresenta-se ao mesmo tempo como a própria sociedade, como uma parte da sociedade e como instrumento de unificação. Como parte da sociedade, ele é expressamente o setor que concentra todo o olhar e toda a consciência. Pelo fato de esse setor estar separado, ele é o lugar do olhar iludido e da falsa consciência; a unificação que realiza é tão-somente a linguagem oficial da separação generalizada.

Debord afirma que a sociedade atual vive num mundo onde as fronteiras entre o real e o espetacular, entre fato e ficção, não são mais passíveis de serem delimitadas, "[...] a realidade vivida é materialmente invadida pela contemplação do espetáculo e retoma em si a ordem espetacular à qual adere de forma positiva. [...] a realidade surge no espetáculo, e o espetáculo é real. " (Debord, 1997, p. 15). Segundo este mesmo autor

relação espetacular que a vida cotidiana adquire é problemática uma vez que a contemplação leva ao entorpecimento, a uma falsa ilusão de se estar vivendo o que naverdade apenas se contempla; o homem, ao se identificar com imagens dominantes, deixa de perceber sua existência e seus desejos pessoais. (1997, p. 15).

O teatro encontra, então, o desafio de estabelecer uma tensão produtiva entre a encenação, enquanto encontro social, e apresentação espetacular, pois o fenômeno teatral almeja distinguir-se do que Debord chamou de espetáculo. A diferença consiste no fato de que o intuito dos teatros criados dentro da lógica representacional pós-dramática é justamente fazer o público consciente das lógicas espetaculares existentes no teatro e na vida, e, neste sentido, co-responsável pela apresentação do espetáculo através do conflito proposto no aqui e agora do encontro teatral (não entre personagens, mas entre as pessoas que participam deste encontro). A operação cênica estabelecida aqui se dá de forma incessante por meio da ironia. O diálogo com o público, do estar representando e negá-lo, criando uma espécie de ironia de discurso que não se resol- 
ve. Ou será que se resolve na não resolução?

Esta condição do teatro pós-dramático em que o espectador se depara com a falta de uma fábula tradicional (com começo, meio e fim), em que ele se encontra diante de uma obra fragmentada e aberta, não apenas porque o final é incerto, mas porque todo o seu enredo parece não seguir uma lógica linear, um contínuo. Segue apenas a si própria e a nova relação. A ironia pode conduzir o seu sentido, mesmo que este não precise de sentido algum, assumir uma posição ativa nessas obras, que esperam do espectador construção de uma visão própria frente ao que lhe é apresentado, uma vez que não existe um todo concreto e acabado, as visões que surgiram em relação ao espetáculo serão múltiplas e particulares. É a mola propulsora para que o teatro seja para o público "um momento que descobre sua possibilidade de ser não apenas um acontecimento de exceção, mas uma situação provocadora para todos os envolvidos". (Lehamann, 1999, p. 172)

Devido à peça se encerrar com insultos, a atuação dos atores (que, na "realidade", para o texto teatral de Hadke, são os próprios espectadores) expande-se para a realidade. $O$ insulto torna-se uma tentativa de tirar da inércia o próprio público. Às vezes, o teatro configura-se como pós-dramático, mas a vida tende a buscar a construção do teatro burguês no que se refere à sua linearidade e romances impossíveis. Mas é a ironia a validadora e a canalizadora destes "insultos" proferidos em formato irônico para abrir a questão do ser e a do não ser, do insulto que, ao mesmo tempo, é texto e insulto. Do sair do lugar de conforto para abrir novas possibilidades de realidade.

Quando se chega ao final da peça, os atores revelam que ela é o prólogo da vida e subli- nham inclusive que os atores é que são os espectadores (e vice-versa). Os atores estiveram no palco e, portanto, não houve ilusão. Diante da perda desta, a ironia é uma das saídas. Para Hans Thies-Lehmann (1999), de certa forma, o teatro significa tempo de vida comum entre atores e espectadores, já quese encontram frente a frente e respiram juntos no mesmo espaço em que a peça teatral acontece. Handke sublinha isso por meio do jogo de iluminação da encenação e sugere, na preparação, o gradativo apagar das luzes; durante a representação, iluminação igual sobre a platéia e sobre os atores e, no final, uma luz mais intensa sobre aquela com a penumbra para o palco.

Mas antes disso os senhores serão insultados. Serão insultados por que o insulto também é uma maneira de falar com os senhores. Na medida que os insultamos podemos torna-nos imediatos. Podemos fazer pular uma faísca. Podemos destruir o espaço fictício, podemos nota-los. Pelo fato de insultarmos os senhores, os senhores não mais nos escutarão. Ouvi-nos-ão. A distância entre nós e os senhores não será mais infinita. Pelo fato de serem insultados, a usa imobilidade e frigidez parecerão finalmente adequadas. Mas nós não insultaremos os senhores, apenas empregaremos insultos que os senhores empregam. Nestes insultos contradizermo-nos. Nunca falaremos a sério, só formaremos uma imagem sonora. Os senhores não precisam se sentir atingidos. Mas como os senhores foram avisados com antecedência, os senhores podem se sentir purificados enquanto os insultamos. E como você já é quase um insulto, falaremos de eu para você. Vocês são o tema de nossos assuntos. Vocês vão nos ouvir seus paspalhos (Handke, s/d, p.14)

É esta grande consciência do autor a respeito da natureza de sua experimentação que permite ligar a experiência cênica à experiência de vida através da dialética e da ironia sobre o 
insulto. A negação de uma peça e os insultos dizem pelo desdizer. Cabe ainda destacar que, Recebido: 27/05/2017 para a peça da vida, no seu pós-drama, reste Aprovado: 26/08/2017 talvez a ironia como saída.

\section{Referências}

ARNOLD, H. L. (Org.) Theater fürs 21.

Jahrhundert. München: Edition Text + Kritik, 2004, p. 8 - 25.

DEBORD, G. A sociedade do espetáculo. Rio de Janeiro: Contraponto, 1997.

FINTER, H. A teatralidade e o teatro. Camarim - publicação da cooperativa paulista de teatro, São Paulo, n. 39, p. 8-19, 2007.

HANDKE, Peter. Insulto ao público (cópia digitalizada). Trad. George Speerber. Rio de Janeiro: UNIRIO, s/d.

LEHMANN, H. Teatro pós-dramático. Trad. Pedro Süssekind. São Paulo: CosacNaify, 2007.

MATERNO, A. Palavra, voz e imagem nos teatros de Valère Novarina, Peter Handke e Samuel Beckett.In: WERNECK, M. (Orgs.). Texto e imagem, estudos de teatro. Rio de Janeiro: 7Letras, 2009.

PORTELA, E. A constelação da ironia: curso oferecido pelo departamento de Ciência da Literatura da UFRJ, 2013. Notas.

SZONDI, P. Teoria do drama moderno [1880 - 1950]. Trad. Luiz Sérgio Repa. SãoPaulo:

CosacNaify, 2001. 